\title{
PROBLEMATIZAÇÃO DA EXPERIÊNCIA E CUIDADO PARRÉSICO NOS PROCESSOS EDUCATIVOS
}

\author{
I. CAMPOS*, W. M. LIMA
Universidade Federal de Alagoas
icec.campos@gmail.com \\ Submetido 14/08/2017 - Aceito 13/04/2018 \\ DOI: $10.15628 /$ holos.2018.6849
}

\section{RESUMO}

O presente artigo discute a utilização da parrésia, ferramenta conceitual explorada por Michel Foucault, em seu pensamento tardio, como elemento indutor e catalisador ético da problematização da experiência, de modo a propiciar e acelerar a ethopoiésis do educando em um mundo plural e sem absolutos. Além do aporte teórico foucaultiano, utilizamos do referencial teórico de Michel Fabre para pensarmos a correlação entre parrésia e experiência, concluindo com indicações de uma problematização no campo da eticidade, para os processos educativos, entre parrésia e experiência.

PALAVRAS-CHAVE: Filosofia da Educação, Sistemas pedagógicos, Parrésia, Problematização da experiência.

\section{PROBLEMATIZATION OF EXPERIENCE AND PARRHESIC CARE ON EDUCATIVE PROCESSES}

\section{ABSTRACT}

This paper discusses the use of parrhesia (greek $\pi \alpha \rho \rho \eta \sigma i \alpha)$, a conceptual tool explored by Michel Foucault, in his late thinking, as booster and ethical catalyst for articulating experience issues, to enable and accelerate the ethopoiésis of the learner in a plural and non-absolute world. In addition to the theoretical
\end{abstract}

contribution of Foucault, the Michel Fabre's theoretical framework was used to reflect on the correlation between parrhesia and experience. It is concluded by indicating discussions on the Ethics field for educational processes between parrhesia and experience.

KEYWORDS: Philosophy of education, Pedagogical systems, Parrhesia, Problematization of experience. 


\section{INTRODUÇÃO}

Os processos educacionais têm, por base, em larga medida, um ensino logocêntrico, com o domínio cognitivo prevalente sobre o domínio das emoções. Uma razão instrumental, nesse contexto, transpõe a singularidade das relações intersubjetivas para o plano da substitubilidade e da funcionalidade (Fonseca \& Enéas, 2011), degradando um tecido ético integrador e diretivo para as ações humanas.

Essa funcionalidade nas relações humanas, por especificidade, nas relações entre educadores e educandos, provoca uma dessensibilização tendente à obnubilação da alteridade, decorrente da imposição de heteronomias dominantes - mercadológicas, científicas, políticas e culturais - que tendem à desertificação ou estilhaçamento da totalidade da experiência, entendendo como experiência o que se passa no sujeito e o transforma, possibilitando novas experiências.

Com efeito, a experiência é um conceito triangular. No plano das faculdades, ela é apresentada como cognição, imaginação e sensibilidade. No plano ético, como autorreflexão e relação autêntica com o outro. No plano temporal, por sua vez, compreende a experiência na dimensão da espontaneidade e da inexauriência (Silva, 2001). Como desenvolvimento do plano da intersubjetividade, Sennett (2001, p. 26) consigna que a "cooperação informal e inconclusa é a melhor forma de vivenciar a experiência".

Informal, porquanto as relações entre pessoas com interesses e habilidades distintas são mais ricas quando não há uma regulação prévia formal. Inconclusa, vez que se busca conhecer o outro sem um objetivo específico, espontaneamente, portanto, sem a busca predeterminada de um ponto de chegada. Cooperação, por fim, vez que prolífica para ambos esses relacionamentos, em contraponto a modelos relacionais padronizados, predelineados, com base na rigidez, na utilidade e na competição (Sennett, 2011).

Isso implica, no campo da Educação, em especial da Educação Escolar, uma transformação em que a tônica curricular se retrai e a liberdade docente e a discente no ensino e na aprendizagem se protraem (Subirats, 2000).

Em sinergia com tal perspectiva, a experiência nas práticas educativas deve ser problematizada, ou seja, desenvolvida por meio de questionamentos estruturantes de problemas e de condições e de dados para sua resolução (Fabre \& Musquet, 2009). Nesse processo, plasmado em uma perspectiva dialógica e colaborativa, Michel Fabre (2015) sugere a utilização e a articulação de elementos pedagógicos indutores e catalisadores da problematização da experiência.

Os indutores da problematização relacionam-se à estruturação do espaço cognitivoracional em que são construídos e articulados dados, condições e hipóteses diante de uma situação-problema (Fabre, 2015).

A seu turno, os catalisadores da problematização ligam-se à carga emotiva ou sensitiva na estruturação da experiência, constituindo um elemento de sua intensificação (Fabre, 2015), a descortinar um viés epistemológico educacional de transitividade entre a escola e a vida. 
O presente artigo discute a utilização da parrésia, ferramenta conceitual explorada por Michel Foucault em seu pensamento tardio, como elemento indutor e catalisador ético da problematização da experiência, de modo a propiciar e acelerar a ethopoiésis do educando em um mundo plural e sem absolutos (Fabre, 2016).

\section{PARRÉSIA: PRÁTICA DA LIBERDADE E DA ALTERIDADE}

Em sentido amplo, parrésia significa dizer-franco, dizer-verdadeiro ou dizer-livre. Etimologicamente, parrhesía, ${ }^{1}$ transliteração do grego $\pi \alpha \rho \rho \eta \sigma i \alpha$, significa tudo dizer, segundo Michel Foucault (2010), sendo traduzida pelos latinos como libertas (Foucault, 2006a), licentia (Foucault, 2010) ou oratio libera (Lausberg, 2004).

Embora a polissemia do vocábulo parrésia obste a fixação de um conceito preciso que se adapte a todos os contextos em que ela foi utilizada ou mencionada, do século $\mathrm{V}$ a.C. até o século $\checkmark$ d.C., nos campos político, filosófico e religioso (Foucault, 2010), na primeira das seis palestras que proferiu em Berkeley em 1983, Foucault $(2013$, p. 9) assim a define:

parrhesia é uma atividade verbal na qual o falante expressa seu relacionamento pessoal com a verdade e arrisca sua vida porque ele reconhece o dizer a verdade como um dever para melhorar ou ajudar outras pessoas (assim como a si mesmo). Na parrhesia, o falante usa sua liberdade e escolhe a franqueza ao invés de persuasão, a verdade ao invés da falsidade ou silêncio, o risco de morte no lugar da vida e da segurança, a crítica ao invés de bajulação e o dever moral ao invés do interesse próprio e da apatia moral.

As primeiras ocorrências do referido termo na literatura grega se situam no século $V$ a.C., nas tragédias de Eurípides (484-407 a.C.). Trata-se da parrésia de cariz predominantemente político, no âmbito da democracia ateniense, como direito de ascendência ou distinção pelo exercício da palavra, forma que não se estendeu à tradição (Foucault, 2013).

Com o desenvolvimento das monarquias no período helenístico, a parrésia se desatrela do aspecto estritamente político (parrésia democrática), passando a ser exercida nas relações entre o conselheiro e o rei (parrésia monárquica), em específico, voltada ao governo de si para o governo dos outros (Foucault, 2010).

Aproxima-se, nesse sentido ético, da parrésia socrática, relacionada às práticas de direção da consciência e da existência (Foucault, 2011), em que o cuidado de si é realizado por meio do cuidado do outro que exerce a parrésia, tradição iniciada no pensamento grego, tendo como referência a obra Górgias, de Platão (Foucault, 2010), e que se desenvolveu sob diferentes formas na filosofia greco-romana, a exemplo do cinismo, do epicurismo e do estoicismo.

Judith Revel (2005, p. 33) define o cuidado de si como o "conjunto das experiências e das técnicas que o sujeito elabora e que o ajudam a se transformar a si mesmo", visando a uma melhor preparação e a uma ação diante das situações da vida, implicando a aquisição de conhecimentos (mathesis) e treinamentos práticos sobre si próprio (áskesis), sejam espirituais ou corpóreos (Foucault, 2011). Seguindo esta perspectiva, parrésia é uma das técnicas fundamentais das práticas de si mesmo.

Ultrapassa-se o conhecimento de si para plasmar o próprio modo de ser do sujeito (Revel, 2005), em uma estética da existência que se ensaia como experiência de si mesmo e se acede 
pelo compromisso e pela constituição de uma autenticidade moral (Larrosa, 2004), mediante a parrésia do mestre.

Assim, o cuidado de si não se relaciona a um processo estanque de interiorização psicológica, tampouco ao egoísmo ou ao culto narcísico (Gros, 2012). Exerce-se, ao revés, mediante o componente moral da alteridade, em específico, pela veridicção parrésica, caracterizada não como discurso teorético-científico ou "estrutura racional do discurso" (Foucault, 2010, p. 54), mas como investidura completa do parresiasta na atividade verbal por ele desempenhada (Glansdorff, 2010), o qual assume um risco ao, ligando seu logos ao seu bios, dizer-franco cuidando do interlocutor.

Como assinala Glansdorff (2010, p. 72), a parrésia "não se reduz a um saber institucionalizado e inevitavelmente produzido por jogos de poder, mas a eles se confronta, informando o ethos daquele que a pratica".

A relação entre cuidado de si e parrésia pressupõe indissociabilidade entre risco e generosidade (Foucault, 2006a). É que a franqueza corajosa implica o risco de desagradar, de ferir, de irritar, no limite de ir até a violência em relação a quem fala (Foucault, 2011), embora a parrésia filosófica busque promover uma verdade de si que não exclua a dimensão da sociabilidade e que limite a violência como forma de vida.

Por outro lado, a parrésia é contrária à bajulação, esta como espelho discursivo retórico da vaidade do outro, a conflitar com o autoconhecimento que a função crítica que a primeira exerce sobre o interlocutor (Foucault, 2012). Difere, ainda, do enfrentamento vociferante ou da disputa (Foucault, 2010), porquanto o cuidado de si se realiza pelo cuidado do outro que tem a coragem do dizer-franco e verdadeiro, possibilitando o confronto das contradições intersubjetivas, gerando alternativas aos problemas.

Deveras é a alteridade que caracteriza o valor moral da coragem (Compte-Sponville, 1995), para além da estima desse caráter ou disposição psicológica, a uma distância da covardia e do que é temerário (Aristóteles, 2005). Nas palavras de Foucault (2006a, p. 465), “a generosidade com o outro está no cerne da obrigação moral da parrésia".

No aspecto ético normativo, a prática parrésica não impõe nem determina as ações do discípulo, inexistindo, pois, coercitividade (Foucault, 2013), não havendo, por conseguinte, parrésia sem questionamento do discípulo.

Em sentido inverso, o dizer-a-verdade parrésico é um dever, mas no sentido ético. Nada o coage nesse sentido. É dever moral e liberdade, portanto (Foucault, 2013).

Tanto o cuidado de si como a parrésia ou a figura do parresiasta não são categorias descobertas na Antiguidade a serem transpostas para a atualidade (Foucault, 2006b).

Não se trata de recuperá-las, mas de utilizá-las como ferramentas conceituais para a construção de práticas educacionais que enfrentem os desafios de um mundo problemático.

A problematização de si ou o cuidado de si, na busca de uma vida verdadeira ou de uma estética da existência, emerge em face da quebrantação de um código fixo e unirreferente de normas morais a serem obedecidas (Foucault, 2006b), ethos no qual a epistemologia do problema de Michel Fabre encontra eco. 


\section{PARRÉSIA E PEDAGOGIA: DA DIFERENCIAÇÃO À CONJUNÇÃO}

Foucault, nas obras tardias que estudam a Antiguidade grega e romana, assinala que a parrésia e o ensino professoral ou técnico-instrucional são modalidades de veridicção. Embora não haja necessariamente uma estanqueidade entre ambos, a parrésia pressupõe risco e ausência de vínculo interpessoal permanente, ao passo que o segundo implica inassunção de risco e busca de vínculo quanto à transmissão do saber ou à pessoalidade (Foucault, 2011).

Além disso, a pedagogia identifica-se com o ensino de aptidões e técnicas previamente constituídas, diferenciando-se do cuidado de si pelo outro, o qual busca a modificação do próprio ser, tendo, portanto, um papel etopoiético (Foucault, 2006a).

Terceira distinção apontada pelo autor, a pedagogia supõe gradualidade no ensino de competências, ou seja, uma metodologia ou maneira ínsita ao processo de aprendizagem, enquanto a parrésia é prática, muitas vezes, abrupta, direta e áspera (Foucault, 2010).

Considerando a concepção epistemológico-educacional desenvolvida por Fabre, as diferenças entre parrésia e pedagogia diminuem. Em ambas, há ativação da experiência, modulação prudencial (embora variável), envolvimento do discípulo na situação-problema, risco, ethopoiésis, temporariedade da relação intersubjetiva e ausência de rigor estrito quanto à previsibilidade e controle dos resultados.

No âmbito da pedagogia do problema de Fabre, a organização da experiência é representada metaforicamente por dois instrumentos geográficos, a bússola e o mapa, que, articulados, possibilitam a orientação do educando para que ele, por si próprio, escolha e siga seu caminho nesse mundo problemático.

A bússola representa a abertura e a polarização do espaço cognitivo em quatro pontos cardinais: condição, dados, problema e solução (Fabre, 2015). Os dados e as condições concernem ao posicionamento e à construção do problema. Da articulação dos dados e das condições, surgem hipóteses a serem validadas ou infirmadas posteriormente (Fabre \& Musquet, 2009).

Por sua vez, o mapa, oferecendo os dados e as condições do problema, representa a descrição das experiências passadas, o iter histórico-cultural percorrido pela humanidade, individualmente, pelo educador, servindo como pontos de referência (Fabre, 2015), sem que o mapa dite a experiência singular do educando.

$\mathrm{Na}$ relação parrésica, como na pedagógica, além das similitudes acima elencadas, o componente da pessoalidade é essencial. $O$ anonimato do parresiasta é a própria supressão da parrésia, assim como o anonimato do professor, silenciado pelo discurso neutral da técnica, é a supressão da intersubjetividade ética no plano educacional.

Aproximando essa teorização da perspectiva parrésica, o educador parresiasta, trabalhando a bússola e o mapa com o educando, poderia, na construção e desenvolvimento dos processos educativos, dizer a verdade de si, quebrantando ou relativizando a hegemonia curricular centrada nas ciências e aproximando o ensino formal da intersubjetividade real das relações humanas, a buscar uma vida verdadeira que transcenda heteronomias voltadas apenas para a enformação e atuação profissional mercadológica. 
A Educação, entendendo aqui educação escolar, tem, portanto, de considerar a subjetividade e a singularidade do educador e do educando, renunciando às pretensões científicas de controle, previsão e quantificação (Gallo, 2004), é dizer uma massificação tendente à redução da realização das potencialidades do ser humano como agente e interagente na sociedade.

Além disso, dizer a verdade nas práticas de autoconstrução ética é uma via para diminuir a violência, física ou verbal, já que as barreiras institucionais estruturadas em relações de poder, que ignoram as volições e experiências do educando, são sujeitas ao enfrentamento e à deslegitimidade por parte dos discentes.

A parrésia, portanto, inerente à dimensão ética da experiência, pode ser um elemento que sirva para transpor as barreiras de assujeitamento e de violência no campo educacional, contribuindo para a autoconstituição ética do sujeito em um plano de transitividade entre a vida e a escola (Pagni, 2011).

Essa perspectiva contempla uma abordagem retórica em relação aos valores do educador e da heterogeneidade discente na qualidade de "negociação das diferenças entre os indivíduos sobre uma determinada questão" (Meyer, 2011, p. 10), de modo a aproximar o ensino do cotidiano e dos problemas dos educandos.

A parrésia, apesar de aparentemente estar centralizada no mestre, é um "jogo" entre dois personagens; desenvolve-se entre ambos, pois o discípulo deve provocar a voz do mestre, e o mestre, por sua vez, responder a ela (Foucault, 2012).

Porém, outra forma de parrésia filosófica na Antiguidade é a da "abertura recíproca" (Foucault, 2012), ambas afirmando e buscando sua própria verdade (Foucault, 2010), diferentemente daquela centralizada no mestre, provocada todavia pelo discípulo (Foucault, 2012).

\section{PARRÉSIA COMO ELEMENTO INDUTOR E CATALISADOR ÉTICO DA PROBLEMATIZAÇÃO DA EXPERIÊNCIA}

A parrésia, uma das técnicas do cuidado de si na Antiguidade (Foucault, 2010), compreendida como "eixo gerador de experiências na e com a verdade, capaz de afetar os sujeitos ali envolvidos" (Carvalho, 2011, p. 17), pode ser utilizada como elemento indutor e catalisador ético na organização da experiência do educando e do educador.

A respeito dos indutores da problematização, Fabre (2015, p. 124) assim aduz:

Os indutores são elementos do meio pedagógico (maneira de questionar, de dar diretrizes, de fornecer informações...) destinados a iniciar no aluno uma busca de dados, de condições ou de resolução do problema. Não se trata de dar prontos esses elementos, nem de deixar o aluno procurá-los sem auxílio. Os indutores podem ser elementos concebidos intencionalmente na preparação do professor: uma maneira específica de pôr as questões, de atrair a atenção sobre as singularidades, de estruturar os dados, de prefigurar as condições, de encaminhar soluções. Mas o professor experiente pode tomar as proposições dos alunos e reformulá-las para fazer avançar a problematização. 
A parrésia, como atividade verbal racional, pode figurar na organização da abertura e polarização do espaço cognitivo, buscando a problematização de situações diretamente relacionadas à ethopoiésis do aluno, diante de uma estrutura social enformadora de subjetividades.

Por outro lado, na liberdade, na franqueza, na coragem e no risco, a parrésia pode ser concebida e desenvolvida como um elemento catalisador da experiência, participando do processo de problematização, ativando o domínio metacognitivo do educando através da sensibilidade ou da emoção provocada pelo impacto positivo que ela busca promover.

Os catalisadores, nessa medida, fortalecem ou implicam o aprendizado através de uma dramatização da experiência, relacionada à resolução de problemas através de desafios ou provas a serem superados pelo aluno, propiciando, assim, uma vivência mais ampla e completa dessa experiência (Fabre, 2015).

Deve haver uma articulação entre indutores e catalisadores da problematização, aliando o domínio cognitivo ao domínio da sensibilidade positiva formadora para a vida.

Certa modulação dos catalisadores parrésicos, com certeza, seria necessária, sob pena de subverter a função preparatória da Educação. Porém é certo que a prática verbal direta, franca e verdadeira, dentro de um ethos institucional adequado, vem contribuir para práticas emancipatórias, auxiliadas pela palavra livre e verdadeira do educador e do educando.

\section{CONCLUSÃO}

Pensar as práticas de espiritualidade na Antiguidade grega e romana na contemporaneidade em dialogia com a Educação implica uma epistemologia pedagógica que pressupõe novas formas de relacionamento entre docência-discência e entre os próprios discentes, menos enrijecidas pelo saber institucional e mais direcionadas ao cuidado de si.

Isso implica uma estrutura favorável ao desenvolvimento desse cuidado parrésico, inclusive em uma reformulação de projetos pedagógicos que privilegiem a controlabilidade e a quietude submissa e passiva do alunado, subestimando a coragem em nome de uma falsa e silenciosa prudência, que pode legitimar violências e injustiças.

A busca de uma estilística da existência na educação requer uma ascese incompatível com um modelo educacional que busca reproduzir, reificar e padronizar comportamentos nas relações de ensino e aprendizagem.

Nesse sentido, o anonimato do parresiasta é a própria supressão da parrésia; o anonimato do professor, a ausência de intersubjetividade ética no plano educacional.

As relações entre a função etopoiética que a prática parrésica promove e a dissolução ou diminuição de barreiras que propiciam a violência no meio educacional constituem rico campo de exploração, assim como a criação de mecanismos que promovam acordos parrésicos que não se percam em programas de direitos e deveres, tampouco em vociferância oposta ao cuidado de si. 
A inserção, nas práticas educativas, da parrésia como elemento indutor e catalisador da problematização da experiência permite enriquecer o ambiente pedagógico e direcioná-lo a instâncias mais altas de autoconstituição ética.

Afinal, as relações de si consigo são o ponto primeiro e último de resistência nas relações de poder (Foucault, 2006a), como abertura de possiblidades de transformação de si e do mundo (Revel, 2005).

\section{REFERÊNCIAS}

Aristóteles (2009). Ética a Nicômaco. São Paulo: Atlas.

Carvalho, A. F. de (2011). Função-educador: em busca de uma noção intercessora a favor de experiências de subjetividades ativas. In A. de Resende (Org.), Transversais entre educação, filosofia e história (pp. 9-24). Belo Horizonte: Autêntica.

Comte-Sponville, A. (1995). Pequeno tratado das grandes virtudes. São Paulo: Martins Fontes.

Dinucci, A., \& Silva, M. A. da. (Ed.) (2013). Prometeus. Filosofia em revista, 13. Recuperado de https://seer.ufs.br/index.php/prometeus/issue/view/157

Fabre, M. (2016). Vivre et éduquer sans absolu. Le Télémaque, 50, 41-46. Recuperado de https://www.cairn.info/revue-le-telemaque-2016-2-p-41.htm. doi: 10.3917/tele.050.0041

Fabre, M. (2015). Éduquer pour un monde problématique. Paris: PUF.

Fabre, M., \& Musquer, A. (2009). Les inducteurs de la problématisation. Les Sciences de l'éducation - Pour l'Ère nouvelle, 42, 111-129. Recuperado de https://www.cairn.info/revueles-sciences-de-l-education-pour-l-ere-nouvelle-2009-3-page-111.html. doi: 10.3917/Isdle.423.0111

Fonseca, A. S. de, \& Enéas, L. F. P. (2011). Por um reencantamento da educação. In F. A. de Andrade, \& J. M. C. T. Santos (Orgs.), Formação de professores e pesquisas em educação: teorias, metodologias, práticas e experiências docentes (pp. 15-31). Fortaleza: Edições UFC.

Foucault, M. (2012). La parrêsia. Anabases. Traditions et réceptions de l'Antiquité, 16, 157-188. Recuperado de http://journals.openedition.org/anabases/3859

Foucault, M. (2011). A coragem da verdade. O governo de si e dos outros II. Curso no Collège de France (1983-1984). São Paulo: Martins Fontes.

Foucault, M. (2010). O governo de si e dos outros. Curso no Collège de France (1982-1983). São Paulo: Martins Fontes.

Foucault, M. (2006a). A hermenêutica do sujeito (2a ed.). São Paulo: Martins Fontes.

Foucault, M. (2006b). Ditos e Escritos V. Ética, Sexualidade e Política (2a ed.) Rio de Janeiro: Forense Universitária.

Gallo, S. (2004). Transversalidade e formação de professores. In C. M. Rivero \& S. Gallo (Orgs.), A formação de professores na sociedade de conhecimento (pp. 101-121). Bauru: Edusc.

Glansdorff, V. (2010). Michel Foucault: la "parrêsia" dans le gouvernement de soi et des autres. Revue de philosophie ancienne, 28(1), 67-84. Recuperado de http://www.jstor.org/action/doBasicSearch?Query=Michel+Foucault\%3A+la+\%E2\%80\%9Cpa rr\%C3\%AAsia\%E2\%80\%9D+dans+le+gouvernement+de+soi+et+des+autres\&filter= 
Gros, F. (2012). Foucault. In J.F. Pradeau (Org.), História da filosofia (2a ed., pp. 490-497). Petrópolis: Vozes; Rio de Janeiro: PUC-Rio.

Larrosa, J. (2004). A operação ensaio: sobre o ensaiar e os ensaiar-se no pensamento, na escrita e na vida. Educação e Realidade, 29(1), 27-43. Recuperado de http://seer.ufrgs.br/index.php/educacaoerealidade/article/view/25417

Lausberg, H. (2004). Elementos de retórica literária (5a ed.). Lisboa: Fundação Calouste Gulbenkian.

Meyer, M. (2011). La rhétorique. Paris: PUF.

Pagni, P. A. (2011) O cuidado de si em Foucault e as suas possibilidades na educação: algumas considerações. In L. A. F. de Souza, T. T. Sabatine, \& B. R. de Magalhães (Orgs.), Michel Foucault: sexualidade, corpo e direito (pp. 19-45). Marília: Oficina Universitária; São Paulo: Cultura Acadêmica.

Revel, J. (2005). Michel Foucault: conceitos essenciais. São Carlos: Claraluz.

Sennett, R. (2011) Humanism. The hedgehog review. Critical reflections on contemporary culture, 13(2), 21-30. Recuperado de http://www.iascculture.org/THR/THR_article_2011_Summer_Sennett.php

Silva, J. D. da. (2001). A Educação para a amplitude da experiência. Perspectiva, 19(2), 331-349. Recuperado de https://periodicos.ufsc.br/index.php/perspectiva/article/view/10232.doi: http://dx.doi.org/10.5007/\%25x

Subirats, M. (2000). A educação do século XXI: a urgência de uma educação moral. In F. Imbernón. (Org.), A educação no século XXI: os desafios do futuro imediato (pp. 195-205). Porto Alegre: Artes Médicas Sul.

\footnotetext{
${ }^{1}$ Embora a literatura utilize a forma transliterada, opta-se pelo uso do vocábulo tal como incorporado no léxico da língua portuguesa, que não se restringe à ousadia verbal ou afirmação corajosa, contemplando igualmente liberdade de palavra ou franqueza. Cf. Houaisss, A. (2009). Dicionário Houaiss da Língua Portuguesa. Rio de Janeiro: Objetiva. Em sentido restrito, Ferreira, A. B. de H. (2004). Novo Dicionário da Língua Portuguesa (3a ed.). Curitiba: Positivo. Rios, D. R. (2007). Novo dicionário global da língua portuguesa ilustrado. São Paulo: DCL. Cunha, A. G. da. (1982). Dicionário etimológico Nova Fronteira da Língua Portuguesa. Rio de Janeiro: Nova Fronteira.
} 